\title{
Meu corpo me pertence: interfaces entre psicologia, dança e gênero
}

\author{
Candela Andrea Ramallo Garcia, (DI) Lara Soutto Mayor Vieira, (DII \\ Marisa Antunes Santiago, (DIII Hebe Signorini Gonçalves $(\mathbb{D})$ II ${ }^{\text {॥ }}$ \\ ${ }^{I}$ Universidade do Estado do Rio de Janeiro, Rio de Janeiro, RJ, Brasil \\ ${ }^{I I}$ Universidade Federal do Rio de Janeiro, Rio de Janeiro, RJ, Brasil

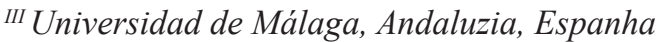

\begin{abstract}
Resumo
Este artigo nasce da inserção da equipe de psicologia numa oficina de dança do Centro de Referência de Mulheres da MaréCarminha Rosa. Através da exploração e (re)conhecimento corporal proporcionado na oficina, percebemos a possibilidade de o corpo da mulher se desprender de uma identidade e se abrir para novos contornos e possibilidades de ser. Assim, o artigo objetiva pensar as interfaces entre psicologia e dança, refletindo sobre as possiveis contribuições destas às reflexões e produções no campo das políticas de gênero. Para tanto, realizaram-se entrevistas semiestruturadas com participantes da oficina e análise dos relatos da equipe de psicologia que acompanhava a oficina. Ao explorar o corpo como ponto de ancoragem da atuação da psicologia e das lutas pela igualdade de gênero, o texto conclui que a conexão entre psicologia, corpo e gênero representa uma possibilidade promissora tanto no que se refere à liberdade subjetiva quanto à superação das formas de dominação de gênero e que ambas as perspectivas merecem ser mais bem exploradas.
\end{abstract}

Palavras-chave: gênero; psicologia; corpo; dança.

\section{My body belongs to me: interfaces between psychology, dance and gender}

\begin{abstract}
This article springs from the introduction of the psychology team in a dance workshop of the Maré Women Reference Center Carminha Rosa. Through exploration and body recognition provided in the workshop, we percieved the possibility to let go of an identity and open up to new dimensions and possibilities of being. Thus, the article aims to think the interfaces between psychology and dance, reflecting on the posible contributions of these reflections and productions in the area of gender policies. For that we have done semi-structured interviews with workshop participants and analysis of the psychology team reports that followed the workshop. By exploring the body as the anchoring point of psychology and gender equality struggles, the text concludes that the connection between psychology, body and gender represents a promising possibility both in terms of subjective freedom and overcoming forms of domination of gender perspective, and these perspectives deserve further exploration.
\end{abstract}

Keywords: gender; psychology; body; dance.

\section{Introdução}

Este artigo surge da experiência das autoras no Centro de Referência de Mulheres da Maré - Carminha Rosa (CRMM-CR), equipamento da Universidade Federal do Rio de Janeiro (UFRJ) e integrante da rede de enfrentamento à violência contra a mulher, prevista nos Planos Nacionais de Políticas para as Mulheres (PNPM), na Política e no Pacto Nacional de Enfrentamento à Violência contra as Mulheres, levados a cabo pela Secretaria de Política para Mulheres (SPM) ${ }^{1}$ e pelos governos estaduais e municipais. Para seu funcionamento, o CRMM-CR tem como orientação a Norma Técnica de Uniformização dos Centros de Referência de Atendimento à Mulher em Situação de Violência.

O CRMM-CR visa, através do atendimento psicológico, social e jurídico, proporcionar instrumentos para que a mulher que tem seus direitos violados possa transformar essa situação. Oferece atendimentos individuais interdisciplinares e oficinas sociais, dentre as quais se encontra a oficina de dança, nosso objeto de estudo. Estas

\footnotetext{
* Endereço para correspondência: Universidade do Estado do Rio de Janeiro. Rua São Francisco Xavier, 524 - Maracanã, Rio de Janeiro, RJ - Brasil. CEP 20550-900.E-mails: candelargarcia@hotmail.com, laravieira05@gmail.com, marisinha.as@gmail.com, hebe@globo.com.

Os dados completos dos autores encontram-se ao final do artigo.

Atual Secretaria Nacional de Políticas para Mulheres, vinculada ao Ministério

da Mulher, da Família e dos Direitos Humanos.
}

oficinas, além de ensinar às mulheres participantes uma técnica (bordados, crochê, dança), pretendem potencializar o exercício da cidadania a partir do reconhecimento dos direitos da mulher e apresentar estratégias e instrumentos para o fortalecimento da autoestima feminina, de forma que as mulheres sejam agentes de sua própria transformação (MARINHO et al., 2012).

O CRMM-CR fica localizado no Complexo da Maré, um conjunto de 16 comunidades localizado na zona norte do Rio de Janeiro. É um espaço onde coexistem poderes e forças conflitantes: o território é disputado entre duas facções do tráfico de drogas e milicianos, além de contar com a ocupação de forças policiais e já ter estado ocupado pelo Exército. Assim, era e ainda é comum haver momentos de confrontos armados entre as facções ou entre estas e a polícia.

A religiosidade está presente nas falas, discursos e nos corpos das frequentadoras da oficina, o que nos parece reforçar uma cultura conservadora quanto ao vestuário e ao comportamento que uma "mulher de bem" ou mãe deve ter.

A oficina de dança era realizada com os propósitos de ensinar técnicas da dança e promover o reconhecimento do próprio corpo, além de se propor a discutir questões de gênero e direitos da mulher, com base na troca de experiência entre as mulheres. A oficina era conduzida por 
alunas do curso de Dança da UFRJ - que aqui chamaremos de instrutoras de dança -, acontecia duas vezes por semana e tinha a duração de duas horas. Poderiam se inscrever quaisquer mulheres, estivessem ou não em situação de violência. A oficina teve início no segundo semestre de 201 e a equipe de psicologia começou a acompanhá-la no início de 2013.

É importante ressaltar que esta oficina não consistia em uma aula de dança tradicional, isto é, não era um espaço que se propunha exclusivamente a ensinar técnicas de dança, como aponta Moura (2015, p. 10-11), psicóloga que também integrou a equipe:

Por entender o corpo como território possível de transformações e local de resgate de sentidos da vida, a proposta da Oficina de Dança é desenvolver estratégias de resgate da cidadania feminina a partir da descoberta e experimentação de si, tendo o corpo como lugar a ser trabalhado, desenvolvido e potencializado.

Segundo o plano de curso das instrutoras de dança, os objetivos da oficina eram fomentar o empoderamento das mulheres através da consciência do corpo e de sua relação com o outro e o espaço circundante; despertar o interesse no conhecimento do próprio corpo, tomando-o em sua totalidade física, mental e emocional; redescobrir e aguçar os sentidos do corpo a partir de um trabalho integrado; proporcionar escape aos automatismos da vida cotidiana a partir do prazer no ato de dançar; estabelecer novas relações com o próprio corpo, com o corpo grupal e nas possibilidades de relação com o espaço; e proporcionar confiança a partir do desenvolvimento de processos de criação da linguagem da dança. Nesse sentido, durante a oficina, as instrutoras promoviam exercícios de alongamento, sensibilização e conscientização corporal.

As aulas começavam com um relaxamento guiado, com as participantes deitadas e atentas às próprias sensações. Havia também exercícios para despertar a atenção para coisas não percebidas costumeiramente: caminhar pela sala observando-a, caminhar olhando nos olhos das pessoas pelas quais passavam. Também eram realizados exercícios em dupla, massageando o outro e sustentando o olhar em silêncio, construindo movimentos conjuntos. Algumas vezes eram propostas atividades com leitura de textos ou vídeos, às quais se seguia uma discussão. Após as atividades de cada oficina havia um lanche, quando as mulheres costumavam conversar. A criação desse momento na oficina tinha o objetivo de proporcionar espaços de falas - verbais - e trocas entre as mulheres, as instrutoras e quem acompanhava a oficina, como veremos adiante.

Além das instrutoras de dança, a oficina contava com a participação de um técnico ou discente de Psicologia, Serviço Social ou Direito, que acompanhava o desenvolvimento das atividades. A inserção de psicólogos na oficina fez parte de seu momento inicial e visava à construção de um espaço onde dança e psicologia pudessem coexistir e dialogar. Desde então surgiram algumas inquietações sobre a intervenção da equipe de psicologia na oficina de dança, que tem como foco principal o trabalho com a dimensão corporal e não com a fala, razão pela qual o escopo de intervenção da psicologia não ficava claro nem parecia usual. Tais inquietações também se deveram ao fato de o papel dos técnicos não estar predefinido, sendo sua participação construída à medida que a oficina acontecia. Cumpre lembrar, ainda, que a conexão aqui proposta - entre a dança, as teorias de gênero e a psicologia - é pouco trabalhada na literatura, uma razão a mais para que as questões aqui apreciadas sejam tomadas em sua vertente de experimentação. Assim, o presente artigo tem como objetivos pensar as interfaces entre psicologia e dança e propor, a partir da experiência aqui discutida, estratégias que possam ser acolhidas no campo das políticas de gênero, já que a oficina em questão também era voltada para o enfrentamento da violência de gênero.

\section{Referencial teórico}

A inserção da Psicologia no espaço de uma oficina de dança parte da premissa de que o corpo, na medida em que não se desvincula de processos psíquicos, pode ser também objeto da Psicologia. Barros (2006, p. 69) acredita que existe no homem moderno uma tendência ao adormecimento e à mecanização da vida, frutos da racionalidade cartesiana:

[...] que afasta o corpo das operações de conhecimento, acreditando-o desprovido de vida ou experiência própria. A cisão mente e corpo reflete-se nos hábitos que contraímos, é constituidora das nossas maneiras de ser, sentir, pensar e agir. Deste modo, a herança cartesiana nos lega um corpo sem vida, um mecanismo.

Nesse sentido, a cisão mente-corpo objetifica o corpo e retira da psicologia a possibilidade de trabalhar com ele, uma vez que, se ele é mero objeto, não há experimentação corporal passível de elaboração psíquica. Esta cisão produz o corpo adormecido cujas conexões com o mundo são negadas: um corpo sem vitalidade, avesso a transformações, sujeitado, insensível.

Entendemos, ao contrário, que a experimentação corporal proporciona a conquista de um novo espaço existencial. Como colocam Moehlecke e Fonseca (2008), a dança propicia o abandono do corpo atual na tentativa de criar novas práticas e modos estéticos de existir. Esse abandono do identitário e da segurança em prol do corpo dançante abre um vazio que guarda a possibilidade de construir outras conexões com o mundo e encontrar formas de existência até então imprevisíveis. A dança se constitui, nesta perspectiva, como modo de subjetivação. Um corpo antes rígido, ao experimentar novos contornos, encontra a possibilidade da mudança, da desconstrução e da potência. A intervenção psicológica pode ser aqui vislumbrada, uma vez que com ela se busca a plasticidade, a transformação e o embate do sujeito com modos de existência que o aprisionam.

O movimento pode mostrar outros caminhos, se explorado para propiciar experiências corporais que provoquem as sensibilidades e tornem mais presentes tanto o próprio corpo quanto os sentimentos que ele elicia; esses corpos seriam "mais aptos a discernir as diferentes qualidades de forças que habitam o mundo. Corpos mais 
conectados, mais articulados, mais ricamente relacionáveis, menos fixados, portanto, mais livres e vitalizados" (BARROS, 2006, p. 112).

Por meio do trabalho corporal e da conscientização e conhecimento do próprio corpo, as mulheres que participaram da oficina também poderiam descobrir novas formas de ser mulher. O despertar para outras possibilidades do e no corpo, isto é, para a construção de novas conexões com o corpo e com a sexualidade, já foi bastante discutido pelo feminismo. Segundo Alves e Pitanguy (2007, p. 61-62), “diretamente relacionado à questão da colocação da mulher como sujeito de sua sexualidade, o movimento feminista [...] propõe uma reapropriação do conhecimento do corpo", partindo da ideia de que este desconhecimento gera alienação e perda da capacidade de controle sobre suas funções.

Outras formas de ser mulher são possíveis através da conexão, do estabelecimento de contato, do estar em relação, ou seja, o que chamamos de afetação. Segundo Lazzarotto e Carvalho (2012, p. 26), o afetar "sinaliza a força de extensão da vida e da atividade que podemos viver". $\mathrm{Na}$ medida em que somos afetados pela experiência, e nos conectamos com o vivido, abrimos a possibilidade de nos experimentarmos de outras formas. Notamos, assim, que a possibilidade de nos afetar, um dos propósitos da oficina de dança, está intimamente relacionada à construção de outras formas de ser sujeito. "Experimentar afetos sinaliza a enunciação de outras formas de agir a partir dos modos de expressão que vamos percorrendo" (LAZZAROTTO; CARVALHO, 2012, p. 26). Assim, ao se mostrarem disponíveis a habitar o espaço da oficina, as mulheres se abrem ao processo de afetação, fundamental para a mudança na forma de estar no mundo.

Outra premissa importante para refletirmos sobre a prática das oficinas de dança é a de que o corpo não é uno, fixo nem estável, mas múltiplo e aberto a transformar-se e construir outras conexões com o mundo. Partimos da visão foucaultiana segundo a qual o corpo é político, visto que as redes de saber/poder incidem na formação dos corpos. Essas relações de saber/poder também abarcam o gênero - o feminino e o masculino - e são marcadas pela submissão e domínio de um pelo outro. Desde seu surgimento, o feminismo indaga as relações de poder entre os gêneros e busca superar formas de organização tradicionais permeadas pela assimetria e pelo autoritarismo, que fizeram com que a mulher fosse desvalorizada e tivesse seu trabalho, sua educação e seus direitos negados ao longo da história (ALVES; PITANGUY, 2007). Cabe lembrar, porém, que identificar a assimetria nas relações de gênero implica localizar possibilidades de resistência:

O "masculino" e o "feminino" são criações culturais e, como tal, são comportamentos apreendidos através do processo de socialização que condiciona diferentemente os sexos para cumprirem funções sociais específicas e diversas. Essa aprendizagem é um processo social. (ALVES; PITANGUY, 2007, p. 55).

Fractal, Rev. Psicol., v. 31 - n. 2, p. 67-75, 2019
Dado que a diferença entre os sexos é histórica, social e cultural - e portanto não natural -, ela é passível de transformação. E dado que o corpo não é prisioneiro de uma única forma de ser, isto é, que ele é múltiplo e abarca um infinito de possibilidades e virtualidades, abre-se a possibilidade de que os corpos das mulheres possam passar da posição de corpos assujeitados para a posição de corpos sujeitos, abertos a modos de ser mulher que não aqueles definidos nas relações de dominação de gênero. ${ }^{2}$

A partir de uma perspectiva cultural do que é ser mulher, impregnada por relações e discursos de dominação de gênero, temos como característica do feminino o desconhecimento do próprio corpo e da própria sexualidade (ALVES et al., 1981). Esse desconhecimento responde ao modelo de pureza definido para a mulher, cria barreiras para a aquisição do saber e do domínio sobre o próprio corpo e é um empecilho para as escolhas e as alternativas de uso do corpo. Então, "se o saber é uma forma de exercício de poder pelo qual o indivíduo traduz e se apropria do mundo, o saber que não deve saber é também uma forma de apropriação condizente com a posição subordinada da mulher" (ALVES et al., 1981, p. 327).

A negação do saber de si possibilita que todo um esquema de sujeição seja desenvolvido e internalizado, alienando, assim, a mulher de seu próprio corpo. Inversamente, podemos pensar que conhecer o corpo e saber de si são atitudes que contribuem para que a mulher possa questionar esquemas de dominação e se constituir como sujeito. O domínio do corpo é capaz de produzir apropriação, emancipação e empoderamento, este entendido como um "processo que desafia as relações de poder instituídas e acontece na tensão individual/coletivo" (MARINHO, 2014, p. 30). O questionamento da posição passiva e a substituição dos valores impostos - produzidos pela cultura e pelos discursos patriarcais - por valores próprios abre caminho para a mudança de atitude diante da agressão, do desrespeito e da desvalorização.

O movimento feminista teve como proposta básica dar voz às mulheres e trouxe no bojo de suas ações a proposição de grupos de reflexão cujos objetivos eram a apropriação pelas mulheres do discurso sobre si e a criação de espaços de manifestação coletiva (ALVES et al., 1981). Segundo Alves e Pitanguy (2007), os grupos de reflexão são também uma estratégia de luta, surgindo da necessidade de romper o isolamento em que vivem a maioria das mulheres. Nesses grupos, a mulher constitui um espaço próprio de expressão em condição de igualdade, sem interferência masculina, onde pode descobrir sua identidade, conhecer-se e verificar que suas vivências não são isoladas, mas partilhadas por outras mulheres (ALVES; PITANGUY, 2007, p. 67), percebendo-se dentro de uma coletividade: "A descoberta dessa experiência comum, a transformação do individual em coletivo, forma a base do

\footnotetext{
${ }^{2}$ Embora as relações de dominação de gênero tendam à assimetria nos lugares e papéis sociais colocados para a mulher em relação ao homem, com isto não pretendemos afirmar que todas as mulheres sejam assujeitadas, nem que a posição de assujeitamento seja a de uma identidade definida e definitiva. Mas, justamente, que esse lugar é passível de mudança.
} 
movimento feminista. Partilhando com outras suas vivências, a mulher reconhece a sua força e conscientiza-se da dimensão política de sua vida particular."

A experiência de compartilhar vivências em grupo nos ajuda a pensar as relações entre psicologia, dança e gênero no espaço da oficina que acompanhamos. Como a arte e, especificamente, a dança, pode produzir processos de transformação e reinvenção de si e do mundo, processos que importam à Psicologia e para os quais ela está atenta? Estes são processos que apontam para o rompimento com padrões e modos de ser predefinidos aos papéis de gênero. Neste sentido:

A arte pode se tornar uma possibilidade consistente de transformação, uma vez que ela ativa uma diluição de antigas certezas e provoca uma construção de novas territorialidades. O paradigma estético nos faz pensar que a vida está em movimento e que temos a chance de romper com aquilo que nos aprisiona, em direção ao intempestivo e à diferenciação. [...] Podemos desnaturalizar aquilo que parecia natural ou estável e provocar novos questionamentos no cotidiano (MOEHLECKE; FONSECA, 2008, p. 375).

Spindler (2005, p. 271) já apontou essa possibilidade a partir das oficinas grupais de dança, para ela um espaço diferente do habitual onde as participantes "poderiam se enxergar e estar em relação de outros jeitos, criando novos dispositivos para dar passagem ao desejo, permitindo uma nova sensibilidade". Do mesmo modo, outros autores defendem que essas estratégias de intervenção permitem o rompimento de hábitos e oferecem:

[...] a possibilidade do corpo ganhar nuances, sutilezas dentro do habitual. A prática, movendo e conscientizando o corpo a partir de diferentes posturas, pode abrir espaços de indeterminação, que serão espaços ainda não significados, mas serão, muito provavelmente, espaços de vitalidade que podem contribuir para a criação de novas maneiras de lidar com a vida (BARROS, 2006, p. 115).

A construção de novas formas de ser mulher a partir de composições imprevisíveis e singulares é um objetivo comum do Movimento Feminista, mesmo considerando a diversidade de feminismos existente. Para o feminismo, a prática política não precisa estar restrita a programas de lutas e reivindicações, visto que o processo de emancipação da mulher dialoga também com as experimentações singulares de mulheres, ou de grupo de mulheres, que descobrem juntas, a cada grupo ou encontro, outras formas de viver segundo novos códigos de comportamento (GREGORI, 1993).

Talvez a força maior, mais importante e menos aparente do movimento feminista esteja na semente de questionamento e de reivindicação que surge na consciência das mulheres que, vivendo o seu cotidiano, vêm tentando transformá-lo e recriar a sua relação com o mundo, com os companheiros, com os filhos, consigo mesmas (ALVES; PITANGUY, 2007, p. 70).

É justamente no despertar desses questionamentos que possibilitam movimentos de consciência das mulheres e recriação de suas relações consigo e com o mundo - que podemos perceber uma articulação entre os objetivos do movimento feminista e as possibilidades despertadas pelo trabalho com o corpo a partir da dança. Através do questionamento, da experimentação e do (re)conhecimento ${ }^{3}$ do corpo, abre-se a possibilidade de "vir a ser". Assim como Simoni e Rickes (2012), entendemos o "vir a ser" como um "outrar", no sentido da produção de uma diferença em relação ao que se está sendo. Segundo as autoras,

Outrar vem então colocar em questão os discursos de identidade, que insistem em relegar à existência uma substancialidade previsível, o que em nada lhe diz respeito. É de Nietzsche (2004) o conhecido aforisma torna-te quem tu és - convite a não temer a dimensão do tornar-se, outrar-se - no qual podemos ler que, de algum modo, existe distância entre onde se está e o que se é (SIMONI; RICKES, 2012, p. 180).

Nesse sentido, consideramos que os exercícios e as discussões realizados durante a oficina de dança convidam as participantes a este movimento de deslocamento de si próprias, abrindo a possibilidade de construírem outras formas de ser mulher. O outramento passa a ser visto como um movimento, que acontece no momento mesmo em que se abre a possibilidade de contato consigo, com o outro que existe em si e com o outro que é externo a si. Outrar é fluxo, é movimento, é processo. É algo que não se pode capturar neste ou naquele exercício, ou que se pode almejar alcançar como uma consequência sine qua non de determinada atividade. Pelo contrário, o outramento de si é acontecimento imprevisível, impossível de controlar:

Outrar sugere ainda, como verbo, que se trata de ação, o que de algum modo implica um sujeito que a empreenda ou sofra. É, no entanto, entre essas duas posições - a saber, as de sujeito à e sujeito de - que o outrar se situa (SIMONI; RICKES, 2012, p. 179).

Dentro desta perspectiva, a oficina de dança permite que as mulheres, a partir da experimentação de seus corpos, da conscientização do que eles podem e da expansão das possibilidades de movimento, criem vazios que possam ser preenchidos de maneiras imprevisíveis, criando novos devires e possibilidades de ser e estar no mundo, permitindo a construção de outras formas de ser mulher e rompendo com os papéis hegemônicos a elas atribuídos.

\section{Metodologia}

Desenvolvemos uma pesquisa qualitativa, na qual foram realizadas entrevistas semiestruturadas com quatro mulheres participantes da oficina de dança e duas instrutoras, cujo roteiro foi construído com base no levantamento e análise dos diários de campo das instrutoras e técnicos que acompanhavam a oficina.

Nas entrevistas com as participantes, que tinham como objetivo explorar os sentidos que a participação na oficina de dança guardava para cada uma das integrantes, foram realizadas perguntas acerca: 1- de sua participação na oficina; 2- de seu interesse e dos motivos que as levaram a frequentar a oficina de dança; 3 - da lembrança de momentos marcantes na oficina; 4- da percepção de alguma mudança em suas vidas com conexão com sua participação; 5- do acompanhamento da equipe de psi-

${ }^{3}$ Optamos pela expressão (re)conhecimento por entendermos que ela representa revisitação do que conhecemos de nós mesmos, uma redefinição e até a redescoberta do que estava adormecido ou esquecido.

Fractal, Rev. Psicol., v. 31 - n. 2, p. 67-75, 2019 
cologia. As entrevistadas foram convidadas a falar sobre sua vivência naquele espaço, sobre as mudanças pessoais após a frequência às oficinas e sobre a participação das instrutoras de dança e dos profissionais de psicologia. Nas entrevistas com as instrutoras foram tratados os referenciais teóricos e metodológicos utilizados no preparo das oficinas, com o objetivo de entender a proposta da oficina e o modo como as instrutoras percebiam a inserção dos alunos e profissionais na atividade.

As entrevistas foram conduzidas por duas das autoras deste texto, que participavam da oficina. A partir de um convite às mulheres que quisessem dar seu depoimento, elas foram realizadas no próprio CRMM-CR, após o término da oficina.

No que se refere ao levantamento e análise dos diários de campo, fazia parte da cultura institucional a produção de narrativas textuais sobre as oficinas por parte de todos os instrutores e profissionais que as acompanhavam, informando a dinâmica de cada uma e registrando observações e avaliações pessoais. Os diários de campo - ferramenta oriunda do campo teórico da Análise Institucional -, utilizados em pesquisa, trazem uma valorosa contribuição metodológica por possibilitarem a análise não apenas do que se passou durante os encontros a partir da descrição dos acontecimentos no campo, mas também das reflexões e afetações de quem os elaborou (LOURAU, 1993). Assim, estes se constituíram também em material importante de análise no presente trabalho.

Todo o material foi submetido à análise com base no referencial teórico da Análise do Discurso:

O discurso é um conjunto de práticas linguísticas que mantêm e promovem certas relações sociais. A análise consiste em estudar como estas práticas atuam no presente mantendo e promovendo estas relações: é trazer à luz o poder da linguagem como uma prática constituinte e de regulação (IÑIGUEZ-RUEDA; ANTAKI, 1994, apud FLORES-PONS; IÑIGUEZ-RUEDA, 2009, p. 690, tradução nossa).

\section{Resultados/Discussão}

A seguir apresentaremos três das categorias de análise que melhor representam o conjunto dos dados coletados nas entrevistas e nos relatos de campo: o (re) conhecimento de si; os outramentos possíveis e as afetações possíveis.

\section{Espelho de Esmeralda: (re)conhecimento de si}

$\mathrm{O}$ primeiro aspecto a ser destacado diz respeito à conscientização e ao (re)conhecimento do corpo promovidos pelos exercícios propostos na oficina de dança. As participantes destacaram que passaram a conhecer partes do corpo que não sabiam existir, como mostra a seguinte fala: "A dança fez que eu descobrisse algumas partes do corpo. Tem, mas você não ativa aquela parte e a dança fez com que eu... entendeu?" (Trecho de entrevista com a participante Sabrina). ${ }^{4}$

Nas entrevistas com as instrutoras de dança, também pudemos colher falas que se conectam a essa dimensão de conscientização corporal. Ao serem perguntadas sobre

\footnotetext{
${ }^{4}$ Todos os nomes apresentados neste artigo são fictícios.
}

os efeitos que percebiam nas mulheres que frequentavam a oficina, as instrutoras disseram que eles eram, sobretudo, corporais, em termos de flexibilidade, equilíbrio e consciência do movimento. Disseram perceber que as participantes, com o passar do tempo, passaram a conhecer mais sobre si e seus próprios corpos e se tornaram capazes, por exemplo, de identificar suas dores (físicas e emocionais) e de localizá-las nos próprios corpos. $\mathrm{O}$ trecho de um diário de campo ilustra o momento em que uma participante, ao realizar o exercício proposto pelas instrutoras, reclama que seu pescoço estava doendo, mas que o exercício tinha possibilitado melhora. O relato de campo abaixo também ilustra o (re)conhecimento do corpo pela participante Samanta:

Durante o lanche, Jandira [instrutora] leu para as mulheres um trecho de um texto, que falava sobre propriocepção [...] e exemplificou [...] falando sobre como nosso corpo fica tenso quando estamos fazendo várias coisas ao mesmo tempo. Samanta lembrou que também podemos ficar assim quando queremos dizer algo para alguém e não dizemos. Contou que isso ocorre com ela, e que ela já reparou que seu corpo fica assim (Diário de campo, maio de 2013).

Essa percepção não é produto do acaso, mas sim efeito ativamente buscado no planejamento das atividades. Durante a oficina, os exercícios, movimentos e atividades eram propostos visando promover um exame mais acurado do corpo, valendo-se da visão, do tato e do movimento.

Agora com todas sentadas nos colchonetes, Jandira e Tatiane [instrutoras] pediram que as mulheres tocassem na pele e no corpo e sentissem esse contato. Propuseram movimentos com os braços e os pés, enrolar e desenrolar de coluna, rotações com pescoço e cabeça, e em certo momento pediram que as mulheres fechassem os olhos e passassem a se olhar com as mãos, com o toque (Diário de campo, julho de 2013).

Este trecho mostra a proposição de um exercício em que as participantes eram convidadas a olhar o corpo com o próprio corpo, através de suas mãos. Um exercício de se tocar, de se conhecer pelo toque, de se aproximar do próprio corpo, de conhecê-lo, de experimentar seus múltiplos componentes e suas múltiplas possibilidades.

Outra consideração obtida por meio das análises das entrevistas e dos relatos de campo, que se conecta ao tema do (re)conhecimento do próprio corpo, é a possibilidade de apropriação, empoderamento e emancipação que o domínio do corpo é capaz de produzir. Para esta discussão, destacamos este trecho de um dos relatos da oficina:

Jandira e Tatiane levaram um texto sobre corpo para ler com as mulheres. O texto [...] afirma que se perde o contato com esse corpo na medida em que temos que, desde muito novos, nos adaptar a regras. [...] Esmeralda deu um exemplo excelente, contou que quando era mais nova havia na casa dela um espelho pequeno e que quando o pai a via se olhando no espelho reclamava e falava para ela parar de perder tempo, já que ela tinha que ir trabalhar na roça. Um dia, quando estava participando de uma dinâmica, em algum grupo de que ela participava, onde tinha que se olhar no espelho, disse que nesse dia ela se viu mesmo e percebeu o quanto era bonita, achou os seus olhos muito bonitos (Diário de campo, março de 2013). 
A passagem acima narra o momento em que Esmeralda, a partir das discussões e vivências do dia durante a oficina, se lembra do momento em que se re-conhece no espelho e, ato contínuo, atualiza este re-conhecimento sobre si e sobre as regras que a impediam de se apropriar dessa vivência. Ao colocar em questão as regras - e reconhecer nelas a razão para não se olhar no espelho -, Esmeralda abre para si mesma a possibilidade de ultrapassá-las, permitindo-se ser e fazer diferente daquilo que reza a regra que a submetia. O "se ver mesmo" e o "se reconhecer bonita" não lhe eram autorizados pelo imperativo do trabalho e do abandono dos cuidados consigo própria.

Outra fala que se conecta à história de Esmeralda e aponta para o (re)conhecimento do próprio corpo é a de Carla, que elogia uma das atividades propostas: “[...] gostei daquela que bota o lençol, eu gostei porque quando tirou o retrato eu vi eu passando no retrato, me reconhecendo. Tá gostando de mim ou não tá, mas tá me reconhecendo" (Entrevista com a participante Carla, setembro de 2013).

Segundo Carla, a atividade permitiu - assim como o espelho de Esmeralda - que ela se identificasse no retrato e pudesse se anunciar na imagem - "esta sou eu" -, num movimento de afirmação de si. Entendemos que este movimento de afirmação de si passa menos pelo reconhecimento de algo que se "é", como em uma essência, e mais pela descoberta daquilo que se pode "vir a ser", a partir do que se é.

\section{O short de Carla: outramentos possíveis}

Outro aspecto que gostaríamos de destacar e considerar a partir da análise do material de pesquisa diz respeito à possibilidade de "vir a ser", de um "outrar" que se conecta com a temática do empoderamento ${ }^{5}$ e é preconizada pelo feminismo através do questionamento, da reivindicação.

A passagem abaixo nos ajuda a pensar sobre a disponibilidade em afetar-se e da potência deste afetar-se (ofertado pela oficina) na construção de outras possibilidades de ser que a oficina de dança pode ajudar a construir:

No final da aula Carla foi ao banheiro e na volta, com um aceno de cabeça e mãos no cantinho da porta, se despediu de nós. Estava vestindo seu short e meia e já se encaminhava à saída, sem a saia e sapatos. Carla estava esquecendo suas vestes na sala e estava indo embora com a roupa que usava para fazer a oficina. Mas estas não eram vestes quaisquer. Carla usa para sair na rua roupas em tons sóbrios, escuros e de comprimento considerável e geralmente vem à oficina com uma longa saia marrom, que lhe chega às canelas. Há algum tempo eu venho reparando que, assim que chega, Carla imediatamente tira a saia e coloca suas meias. O tirar da saia é acompanhado pelo súbito aparecimento de um short de lycra, coladinho e florido, acompanhado de um par de meias não menos coloridas. Mas nesse dia, quando Carla começou a descer as escadas para ir embora trajando seu short colorido e deixando para trás a longa e costumeira saia marrom, algo me chamou a atenção: era a mesma Carla que saía dali naquele dia? Quantas Carlas se

${ }^{5}$ Entendido como a possibilidade de questionamento das relações de poder, a partir de atividades que englobam desde a assertividade individual até a resistência, protesto e mobilização coletivos. "Portanto, empoderamento é um processo dirigido para a transformação da natureza e direção das forças sistêmicas que marginalizam as mulheres e outros setores excluídos em determinados contextos" (SARDENBERG apud BERTH, 2018, p. 16). recriam, a cada dia, a cada encontro, no espaço da oficina. Das vestes longas, escuras e monocromáticas, nascia um short colado, florido, serelepe. Da senhora tensa, tímida e enrijecida, surgia uma mulher despreocupada, risonha e esquecida de sua saia. Esquecida de si. Tornava-se outra (Diário de campo, setembro de 2013).

Acompanhamos, com Carla, a mudança que suas vestes simbolizavam. Com seu short florido, Carla se entregava, com toda a disponibilidade e alegria, aos exercícios e movimentos propostos pelas instrutoras. De posse de seu short, Carla virava outra. Encontrou na oficina de dança a possibilidade de ser outra para além do que vinha sendo. Encontrou ali a possibilidade de sair florida pelas ruas da Maré, na estranheza que aquela outra Carla representava em relação ao comprimento e ao marrom de suas antigas vestes. Nesse momento percebe-se o outrar de Carla.

Outro aspecto deste "outramento" pode ser exemplificado a partir da mudança de postura no cotidiano, destacado nas entrevistas realizadas. Para muitas mulheres que participavam da oficina, seu cotidiano era a casa das tarefas domésticas; a oficina representava a possibilidade de romper com esta rotina, de fazer diferente do que costumavam fazer, de produzir um cotidiano outro. Isto é exemplificado pela fala abaixo, na qual Carla, nosso exemplo de outramento, perguntada sobre o motivo que a levava à oficina, respondeu que "daqui eu saio leve, a preocupação fica tudo pra trás", porque "em casa o que faço mais é meter a mão na louça e lavar e deixar a pia limpa". Isso também é colocado por uma das instrutoras de dança:

Acho que a oficina traz um pouco isso, delas pensarem mais nelas, de dedicarem um momento pra elas, acho que é bom por isso, que as mulheres aqui na Maré, e principalmente nos lugares mais pobres, elas vivem muito pros outros, acho que não só as mais pobres, acho que todas as mulheres, então eu acho que a importância da oficina de dança é ter esse espaço dedicado para a mulher (Entrevista com a instrutora Tatiana, setembro de 2013).

Para Tatiana, o fato de a oficina possibilitar que as mulheres se afastem do lugar de cuidadoras e abram espaço para o cuidado e conhecimento de si é significativo e permite novas configurações de si. Nesse sentido, não só as possibilidades de outras formas de "ser mulher" entram em cena, mas também as possibilidades em relação à idade. Ao longo das oficinas foram muitas as mulheres que colocaram a questão da idade como empecilho para certos movimentos:

[...] com essa aula elas sabem que podem fazer, que elas vieram muito com essa ideia que elas não podem fazer nenhum movimento, que elas não conseguem dançar, que elas não podem dançar por causa da idade, que é uma coisa que elas usam muito. E aos poucos a gente está conseguindo mudar esse pensamento, mostrando a prática, elas estão sentindo, estão vendo que podem fazer (Entrevista com a instrutora Tatiana, setembro de 2013).

Não é apenas a idade que as mulheres colocam como empecilho. Em algumas se percebia a rigidez corporal que, em alguns casos, anunciava maneiras de ser. Deusa, por exemplo, era muito travada nos movimentos durante 
a oficina, mesmo quando lhe eram solicitados movimentos simples. Essa rigidez espelhava a postura defensiva adotada por ela para defender seus pontos de vista; opiniões e corpo se assemelhavam:

Dona Deusa parece muito travada nos movimentos durante a oficina, e mesmo quando Jandira e Tatiana propõem movimentos simples como mexer o ombro, ela diz que não consegue. Às vezes, nem tenta fazer o que é proposto (Diário de campo, junho de 2013).

Ao longo do tempo em que acompanhamos a oficina, foi possível observar alguns avanços das mulheres em suas posturas diante dos exercícios propostos. Participantes que antes faziam movimentos contidos eram vistas rodopiando pela sala, "requebrando" o quadril, de forma solta e expansiva. $\mathrm{O}$ caso de Deusa nos chamou bastante a atenção neste sentido, pois sempre que lhe fosse proposta uma atividade que consistisse em deitar no chão, ou que envolvesse o movimento de agachar, ela se recusava. Houve um dia, porém, em que resolveu arriscar-se em outras possibilidades de movimento e deitou-se no chão, sem hesitar ou questionar, fato comemorado por todos.

Ainda em relação aos exercícios e movimentos corporais propostos na oficina, destacamos um dos que parecem se relacionar ao movimento de "outramento" vivido por Carla e Deusa. Em uma das oficinas, as instrutoras propuseram às participantes uma atividade que consistia em olhar nos olhos umas das outras e reparar em detalhes que ainda não haviam percebido. $\mathrm{O}$ exercício era um convite para perceber quantas "outras" existiam em cada participante: "O desconforto em manter o olhar fixo nos olhos de outra parecia ser geral, e as mulheres desviavam o olhar e riam em alguns momentos" (Diário de campo, julho de 2013).

\section{Pontualidade de Camila: afetações possíveis}

Esta categoria destaca outro aspecto relacionado à dimensão do outramento. Ao relatar a percepção de desconforto entre as participantes, o relato acima aponta para a afetação das participantes diante do exercício proposto. Tomamos afetação aqui como possibilidade de conexão, de estabelecimento de contato, de estar em relação, como abordado na introdução.

O deixar-se afetar, como vimos, é fundamental para a mudança na forma de estar no mundo. Destacamos uma passagem que nos ajuda a pensar sobre este "afetar-se" e contribui para entendermos o quanto o afetar-se ultrapassa a ordem do sentimento:

Antes de a aula começar, porém, Dona Camila já estava lá. Jandira me disse que ela chegara ao Posto de Saúde ainda antes de o Centro abrir. Perguntamos a ela, no fim da aula, porque ela havia chegado tão cedo, ao que ela respondeu que mora longe e vem andando, e por isso ficou com medo de chegar atrasada. Acho que esta situação mostra o quanto Dona Camila tem ficado feliz com as aulas, e sua grande vontade e disponibilidade em participar (Diário de campo, maio de 2013).

Avançando, podemos perceber que a disponibilidade em participar e o desejo de habitar o espaço da oficina inauguram a abertura para o se deixar afetar e ser afetado. A disponibilidade com que as mulheres participavam das atividades propostas foi um aspecto bastante ressaltado nos relatos. Mas a disponibilidade é condição necessária, não suficiente; a ela se conectam a percepção de si, a abertura para o outramento e para a experimentação.

Ao final da aula, Jandira e Tatiana propuseram um exercício de sombra. Achei que um certo desconforto fosse aparecer quando tivéssemos que executar o que era pedido na frente das outras, mas qual não foi minha surpresa ao ver que as mulheres não só faziam o que era pedido sem nenhuma vergonha ou desconforto, mas ao ver a maneira como se entregavam e interpretavam a situação e movimentos requisitados. [...] Ao comando "mostrem como vocês são guerreiras", as mulheres não só faziam os movimentos com as mãos, como foi pedido, mas mostravam toda a garra também no olhar que oscilava da ternura à firmeza, no levantamento das sobrancelhas, na boca que entortava um pouco para a direita. Em certo momento olhei para Silvia, e em sua expressão pude sentir a guerreira que ela estava nos transmitindo naquele momento (Diário de campo, abril de 2013).

A união e a formação de vínculos também foram componentes que apareceram e se conectaram com a dimensão de afetação percebida ao longo das oficinas. Algumas participantes criaram laços de amizade, e a união do grupo foi destacada como aspecto importante em todas as entrevistas realizadas. Nestas e nos relatos examinados percebemos que a atmosfera durante os exercícios era de incentivo, cuidado, respeito com o tempo do outro e de construção de um coletivo no qual as mulheres sentiam-se à vontade para expressar opiniões. Um dos relatos, por exemplo, afirma que uma das participantes negou-se a fazer determinada atividade porque a achava chata, o que foi aceito por todas.

O trecho em questão ilustra a acolhida da recusa e a autorização da divergência, tratadas como elementos que integram e constroem o coletivo. Essa ambiência termina por se constituir no pano de fundo contra o qual as mulheres são livres para se encontrar, se conectar e se afetar mutuamente. Ao se abrirem à relação com o outro, permitem colocar-se e experimentar outras formas de ser, e o respeito entre todas permite que elas possam operar uma relação de igualdade na qual sua voz é respeitada. Nesse sentido, a relação de cuidado, respeito e carinho destacada pelas mulheres nas entrevistas contribui para a disponibilidade de elas habitarem o espaço da oficina, no tocante não apenas à entrega na realização das atividades, mas na maneira de se posicionar naquele espaço, tanto nos movimentos quanto na relação com o outro, tanto no corpo quanto na palavra. O "estar à vontade" no grupo emerge como aspecto vital da possibilidade de afetar-se que, como vimos, pressupõe a abertura para estar com o outro e conectar-se com ele, elemento imprescindível da descoberta de si próprio.

\section{Conclusão}

Os resultados apresentados ilustraram, a partir das três dimensões destacadas - o (re)conhecimento de si, os outramentos possíveis e a afetação -, as possibilidades de conexão entre a dança, a psicologia e as discussões sobre relações de gênero. 
A experiência da equipe de psicologia dentro da oficina de dança produziu inquietações e incertezas quanto às possibilidades de intervenção de nossa área num espaço focado na expressão corporal e inserido em um serviço voltado para o enfrentamento da violência de gênero. No entanto, no momento em que buscamos as interfaces entre a Psicologia e a Dança, percebemos que o corpo, ao não se desvincular dos processos psíquicos, é também objeto da Psicologia, que, por isso, deve ocupar-se dele. Através da exploração corporal e do (re)conhecimento do corpo proporcionado pela oficina, percebemos a possibilidade de este se desprender de identidades fixadas e se abrir a novos contornos e possibilidades de ser. Este desprendimento cria vazios que podem ser preenchidos de formas imprevisíveis. A dança se constitui, assim, em um modo de subjetivação e expressão de singularidades, em que o movimento é motor de construção da flexibilidade do corpo e - seguindo a proposta de Moehlecke e Fonseca (2008) - provoca maior fluidez da própria subjetividade, estabelecendo conexões menos rígidas com o mundo e com os próprios afetos.

Desta forma, pensando que a intervenção da psicologia busca a plasticidade, a transformação e o reexame dos aprisionamentos, podemos perceber que no espaço da oficina de dança essa intervenção é possível. Buscamos, a partir de nossas intervenções, que as participantes se reinventem internamente, (re)elaborando formas de lidar com a vida, tornando-se protagonistas de suas histórias. O conhecimento do próprio corpo e o saber de si contribuem para que as mulheres possam se constituir como sujeitos, possibilitando o questionamento das formas de dominação, de gênero inclusive.

$\mathrm{O}$ (re)conhecimento do corpo proporcionado pela oficina de dança se conecta com as discussões de gênero na medida em que, não sendo o corpo prisioneiro de uma única forma de ser, abre-se a possibilidade de que os corpos das mulheres possam passar da posição de assujeitamento para a posição de sujeitos, corpos abertos a formas outras de ser mulher, para além daquelas predefinidas nas relações de dominação de gênero. Percebemos que dentro da oficina de dança é possível compartilhar experiências, conhecer histórias comuns e edificar um coletivo que colabore para a reflexão acerca do que é "ser mulher", proposta tão cara ao feminismo.

É o espaço assim construído que possibilita repensar o lugar de submissão e desconstruir modos de ser apriorísticos, impostos às mulheres. Como vimos, as participantes da oficina estavam dispostas a serem afetadas e tocadas pelo que a oficina oferecia para além do impacto físico. Essa abertura permitiu que novas experiências entrassem em suas vidas e que elas conhecessem melhor seus corpos. O exemplo do espelho de Esmeralda traz a narrativa do momento em que ela se (re)conheceu no espelho, atualizando este (re)conhecimento sobre si e sobre as regras que impediam essa vivência. A afetação e a disponibilidade para si própria também se observa no exemplo do short de Carla, momento em que uma mulher habituada à roupa longa e escura ostenta, quase desapercebida da própria transformação, o short curto e colorido que não esconde seu corpo. Este momento nos mostra a possibilidade de ser outra(s) para além do que vinha sendo. Carla deixou-se afetar e essa afetação esteve presente na oficina de dança de várias formas: no esforço das mulheres em comparecer à oficina, no respeito de cada uma pelo tempo da outra, na entrega às atividades e na construção de vínculos de amizade para além daquele espaço. Se o feminismo é resistência, re-criação e vida (ALVES; PITANGUY, 2007), então o corpo pode ancorar sua luta.

\section{Informações sobre as autoras:}

\section{Candela Andrea Ramallo Garcia}

(iD) https://orcid.org/0000-0003-4097-2747

(9) http://lattes.cnpq.br/9206070583198840

Possui graduação em Psicologia pela Universidade Federal do Rio de Janeiro (2014). Tem experiência na área de Psicologia, com ênfase em Psicologia Social e Psicologia Jurídica. Experiência de estágio no Centro de Referência de Mulheres da Maré - Carminha Rosa e no DEGASE. Foi psicóloga na instituição de acolhimento para crianças pequenas em Bonsucesso. Especialista em Psicologia Jurídica pela Universidade estadual do Rio de Janeiro (UERJ). Mestranda no programa Políticas Públicas e Formação Humana na UERJ.

\section{Lara Soutto Mayor Vieira \\ (iD) https://orcid.org/0000-0002-6847-9957 \\ (9) http://lattes.cnpq.br/2621195496276310}

Possui graduação em Psicologia pela Universidade Federal do Rio de Janeiro (2015) e Especialização em Residência Multiprofissional em Saúde da Família e Comunidade pelo Instituto de Atenção à Saúde São Francisco de Assis (HESFA/UFRJ) (2018).

\section{Marisa Antunes Santiago \\ iD https://orcid.org/0000-0001-5798-6585 \\ (9) http://lattes.cnpq.br/7577954136727446}

Psicóloga (UFRJ,2006). Mestre em Investigación e Intervención Socioeducativa (Universidad de Málaga/ España, 2009 - revalidado pela UFRJ, em outubro de 2013). Doutora em Investigación e Intervención Social y Comunitária (Universidad de Málaga/ España, 2015), com tese intitulada Una Marea de Historias: Releer la Violencia de Género en una Favela Carioca (http://www.riuma. uma.es/xmlui/handle/10630/9838). Especialista em Políticas de Gênero e Direitos Humanos (UFRJ,2015).

\section{Hebe Signorini Gonçalves \\ (iD) https://orcid.org/0000-0003-1688-9927 \\ (9) http://lattes.cnpq.br/8322065902773532}

Graduada em Psicologia pela Universidade de São Paulo (1975), Mestre (1993) e Doutora (2001) em Psicologia pela Pontifícia Universidade Católica do Rio de Janeiro.

\section{Contribuições das autoras:}

Candela Andrea Ramallo Garcia e Lara Soutto Mayor Vieira participaram da coleta de dados; todos os autores colaboraram ao longo do processo, desde a elaboração até a revisão final do manuscrito. Os autores aprovaram o manuscrito final para publicação.

\section{Como citar este artigo:}

\section{ABNT}

GONÇALVES, Hebe Signorini et al. Meu corpo me pertence: interfaces entre psicologia, dança e gênero. Fractal: Revista de Psicologia, Niterói, v. 31, n. 2, p. 67-75, maio/ago. 2019. https:// doi.org/10.22409/1984-0292/v31i2/5600

\section{APA}

Gonçalves, H. S., Garcia, C. A. R., Vieira, L. S. M., \& Santiago, M. A. (2019). Meu corpo me pertence: interfaces entre psicologia, dança e gênero. Fractal: Revista de Psicologia, 31(2), 67-75. doi: 10.22409/1984-0292/v31i2/5600 


\section{Referências}

ALVES, Branca Moreira; PITANGUY, Jacqueline. O que é feminismo. São Paulo: Brasiliense, 2007.

ALVES, Branca Moreira et al. Espelho de Vênus: identidade social e sexual da mulher. São Paulo: Brasiliense, 1981.

BARRoS, Laura Pozzana de. Sistema Rio-Aberto: o corpo em conexão. 2006. Dissertação (Mestrado em Psicologia) Departamento de Psicologia, Universidade Federal Fluminense, Niterói, 2006

BERTH, Joice. O que é empoderamento? Belo Horizonte: Letramento, 2018.

FLORES-PONS, Gemma.; IÑIGUEZ-RUEDA, Lupicinio. Análisis del discurso tecnocientífico que construye la muerte encefálica en un manual de coordinación de trasplantes. Discurso y Sociedad, Barcelona, v. 3, n. 4, p. 682-713, 2009.

GREGORI, Maria Filomena. Cenas e queixas: um estudo sobre mulheres, relações violentas e a prática feminista. São Paulo: ANPOCS, 1993.

LAZZAROTTO, Gislei Domingas Romanzini; CARVALHO, Julia Dutra de. Afetar. In: FONSECA, Tania Mara Galli; NASCIMENTO, Maria Lívia do; MARASCHIN, Cleci. (Org.). Pesquisar na diferença: um abecedário. Porto Alegre: Sulina, 2012. p. 25-27.

LOURAU, René. René Lourau na Uerj. Análise Institucional e Práticas de Pesquisa. Rio de Janeiro: EDUERJ, 1993.

MARINHO, Paloma Abelin Saldanha. Pedras no caminho? Guardo todas, um dia vou construir um castelo: o processo de empoderamento de mulheres em situação de violência. 2014. Dissertação (Mestrado em Psicologia) - Instituto de Psicologia, Universidade Federal do Rio de Janeiro, Rio de Janeiro. 2014.

MARINHO, Paloma Abelin Saldanha et al. As oficinas sociais e o fortalecimento da autonomia feminina. Brasília: Conselho Federal de Psicologia, 2012. Prêmio Profissional: "Democracia e Cidadania Plena das Mulheres".

MOEHLECKE, Vilene; FONSECA, Tania Mara Galli. O corpo encontra Apolo e Dionísio: potências e fragilidades. Psicol. USP, São Paulo, v. 19, n. 3, p. 375-392, sept. 2008. http:// dx.doi.org/10.1590/S0103-65642008000300007

MOURA, Amanda Duarte. Que corpo é esse? Que pulsa, escuta, expulsa, abraça, comporta, contém: reflexões acerca da inserção de uma psicóloga numa Oficina de Dança. 2015. Monografia (Residência Multidisciplinar em Políticas de Gênero e Direitos Humanos) - Universidade Federal do Rio de Janeiro, Rio de Janeiro. 2015.

SIMONI, Ana Carolina Rios; RICKES, Simone Moschen. Outrar. In: FONSECA, Tania Mara Galli; NASCIMENTO, Maria Lívia do; MARASCHIN, Cleci. Pesquisar na diferença: um abecedário. Porto Alegre: Sulina, 2012. p. 179-181.

SPINDLER, Patrícia. Dança: uma ferramenta potencializadora da subjetividade. Mnemosine, Rio de Janeiro, v. 1, n.1, p. $262-$ 276, 2005. 